University of Wollongong

Research Online

Faculty of Engineering and Information

Faculty of Engineering and Information

Sciences - Papers: Part B

Sciences

2018

Second law analysis for nanofluid turbulent flow inside a circular duct in presence of twisted tape turbulators

M Sheikholeslami

Babol Noshirvani University of Technology

M Jafaryar

Babol Noshirvani University of Technology, MR CFD LLC

Zhixiong Li

Ocean University of China, University of Wollongong, zhixiongli@cumt.edu.cn

Follow this and additional works at: https://ro.uow.edu.au/eispapers1

Part of the Engineering Commons, and the Science and Technology Studies Commons

Research Online is the open access institutional repository for the University of Wollongong. For further information contact the UOW Library: research-pubs@uow.edu.au 


\title{
Second law analysis for nanofluid turbulent flow inside a circular duct in presence of twisted tape turbulators
}

\author{
Abstract \\ Finite volume method is employed to simulate water based nanofluid turbulent flow and entropy \\ generation in a heat exchanger. In order to augment heat transfer rate, twisted tape turbulators insert \\ inside the pipe. Second law analysis are presented for various values of height ratio (BR) and pitch ratio \\ (PR) and Reynolds number (Re). Related formulas for entropy generation and Bejan number are provided. \\ Results indicate that secondary flow increases with increasing number of revolution. Bejan number and \\ total entropy generation augment with augment of pitch ratio. But they decreases with augment of \\ Reynolds number and height ratio.

\section{Disciplines} \\ Engineering | Science and Technology Studies

\section{Publication Details} \\ Sheikholeslami, M., Jafaryar, M. \& Li, Z. (2018). Second law analysis for nanofluid turbulent flow inside a \\ circular duct in presence of twisted tape turbulators. Journal of Molecular Liquids, 263 489-500.
}




\title{
Second law analysis for nanofluid turbulent flow inside a circular duct in presence of twisted tape turbulators
}

\author{
M. Sheikholeslami ${ }^{\text {a }}$, M. Jafaryar ${ }^{\text {a }}$, Zhixiong Li $^{\text {b,c, } 1}$ \\ ${ }^{a}$ Department of Mechanical Engineering, Babol Noshirvani University of Technology, \\ Babol, Islamic Republic of Iran \\ ${ }^{b}$ School of Engineering, Ocean University of China, Qingdao 266110, China \\ ${ }^{c}$ School of Mechanical, Materials, Mechatronic and Biomedical Engineering, University of \\ Wollongong, Wollongong, NSW 2522, Australia
}

\begin{abstract}
Finite volume method is employed to simulate water based nanofluid turbulent flow and entropy generation in a heat exchanger. In order to augment heat transfer rate, twisted tape turbulators insert inside the pipe. Second law analysis are presented for various values of height ratio (BR) and pitch ratio (PR) and Reynolds number (Re). Related formulas for entropy generation and Bejan number are provided. Results indicate that secondary flow increases with increasing number of revolution. Bejan number and total entropy generation augment with augment of pitch ratio. But they decreases with augment of Reynolds number and height ratio.
\end{abstract}

Keywords: Entropy generation; Bejan number; Nanofluid; Twisted tape turbulator; Heat transfer; Turbulent flow.

\section{Nomenclature}

$D \quad$ pipe diameter

\section{Greek symbols}

\footnotetext{
${ }^{1}$ Corresponding author:

Email address: zhixiong.li@knights.ucf.edu, zhixiongli@cumt.edu.cn (Zhixiong Li)
} 
$f \quad$ Darcy friction factor

$B R \quad$ Height ratio

$L \quad$ length of pipe

$b \quad$ Height of the twisted

$\mathrm{Nu} \quad$ Nusselt number

$t \quad$ Thickness of the fin

$\operatorname{Pr} \quad$ Prandtl number

$P \quad$ Pressure

$p \quad$ twisted pitch length

$P R \quad$ Pitch ratio $(=p / D)$

Be Bejan Number

$S_{g e n} \quad$ Entropy generation

$T \quad$ Fluid temperature

Re Reynolds number $\alpha \quad$ Thermal diffusivity

$\mu \quad$ Dynamic viscosity of

nanofluid

$\rho \quad$ Density

$\phi \quad$ Volume fraction of nanofluid

Subscripts

$i$ inner

$0 \quad$ outer

nf nanofluid

$S \quad$ particles

f $\quad$ Base fluid

\section{Introduction}

Recently, second law analysis and entropy generation minimization were considered by several scientists to obtain the optimal design of the thermal systems. Techniques for improving thermal performance of heat exchanger are categorized as 
passive and active techniques. Hassan et al. [1] investigated particle shape influences on nanofluid heat transfer in existence of Lorentz forces. They used water and iron nanoparticles of three different shapes like sphere, oblate ellipsoid and prolate ellipsoid. Raju et al. [2] demonstrated non-Newtonian nanofluid natural convection over a cone. They considered magnetic field effect. They found that the non-uniform heat source/sink parameter is a major controlling parameter of the nanofluid flow and heat transfer rate. Sheikholeslami et al. [3] investigated $\mathrm{CuO}$ nanoparticles transportation in a heat exchanger equipped with helical turbulators. They found that temperature gradient enhances with decrease of pitch ratio. Ellahi et al. [4] investigated mixed convection flow of nanofluid on a vertical stretching porous plate. They presented the correlations of Nusselt number and skin friction corresponding to active parameters. Mwesigye et al. [5] reported the influence of using twisted tape inserts on Bejan number. Sheikholeslami [6] reported the Nano-enhanced PCM solidification process by means of finite element method. He showed that dispersing nanoparticles in to pure PCM can accelerate the solidification.

Suri et al. [7] demonstrated the thermal analysis for a pipe with perforated twisted tapes turbulator. Their indicated that numerous perforated twist tape had better thermal performance. Mehmood et al. [8] demonstrated the migration of nanoparticles in ethylene glycol under the impact of electric field. They used the similarity transformations to reduce the equations in similar forms, then solved by Runge-Kutta scheme. Bhatti et al. [9] investigated entropy generation of ferrofluid in a microchannel. They proved that the entropy profile shows a positive response due to the greater impact of Brinkmann number, magnetic field, and the Joule heating parameter. Influence of Cattaneo-Christov heat flux model on the flow of Maxwell ferromagnetic liquid was analyzed by Rehman et al. [10]. They showed that velocity of the fluid decreases, while 
temperature augments by increasing the values of ferromagnetic interaction parameter. Ahmad and Mustafa [11] studied the rotating flow of nanofluid due to convectively heated exponentially stretching sheet. They found that thermal boundary layer thickness augments and heat transfer rate reduces upon increasing the angular velocity of the rotating fluid. Sheikholeslami and Zeeshan [12] employed LBM for nanofluid flow in an enclosure with elliptic heat source. They showed that convective flow enhances with rise of buoyancy forces. Kumar et al. [13] investigated three dimensional flow of a Prandtl liquid over a flat plate. They considered chemical reaction effect on governing equations. Makinde et al. [14] demonstrated the nanofluid flow considering non uniform viscosity. Haq et al. [15] studied the influences of aligned magnetic field on nanofluid flow over a slip surface. They concluded that SWCNTs-kerosene depicts the high friction and heat transfer rate at the surface as compare to the rest of the mixtures. Raju et al. [16] studied the nanofluid flow over a wedge. They found that the decelerating flow over a wedge is very useful for cooling applications. Zin et al. [17] demonstrated the unsteady MHD natural convection flow of rotating Jeffrey nanofluid saturated in a porous medium. They found that, the rotation parameter tends to decrease the primary velocity but reverse effect is observed in the secondary velocity. Recently, nanofluid considered as interesting passive techniques [18-39].

In this paper, effect of twisted tape turbulator on nanofluid entropy generation in a heat exchanger is studied numerically using FVM. Roles of height ratio, Reynolds number, and pitch ratio on entropy generation of nanofluid have been depicted.

\section{Physical model}


Geometry of turbolentor and sample mesh are shown in Figs. 1 and 2. Lengths, outer and inner diameters of the pipe are 900, 20 and $5 \mathrm{~mm}$, respectively. We separate the length to three regions: inlet section, test section and outlet section. Twisted tape is situated in second section and two other sections are considered to prevent any probable back flow streams. Tables 1 and 2 illustrate properties of $\mathrm{CuO}$ and water.

\section{Mathematical model}

To simulate this article, the governing equations for turbulent flow and forced convection heat transfer of nanofluid are:

$$
\begin{aligned}
& \frac{\partial\left(u_{i}\right)}{\partial x_{i}}=0 \\
& \frac{\partial}{\partial x_{j}}\left(u_{i} u_{j} \rho_{n f}\right)=-\frac{\partial p}{\partial x_{i}}+\frac{\partial}{\partial x_{j}}\left(-\rho_{n f} \overline{u_{j}^{\prime} u_{i}^{\prime}}\right)+\frac{\partial}{\partial x_{j}}\left(\mu_{n f}\left(\frac{\partial u_{i}}{\partial x_{j}}+\frac{\partial u_{j}}{\partial x_{i}}\right)\right) \\
& \frac{\partial}{\partial x_{i}}\left(\rho_{n f} T u_{i}\right)=\frac{\partial}{\partial x_{i}}\left(\left(\Gamma+\Gamma_{t}\right) \frac{\partial T}{\partial x_{i}}\right), \\
& \left(\Gamma=\mu_{n f} / \operatorname{Pr}_{n f}\right),\left(\Gamma_{t}=\mu_{t} / \operatorname{Pr}_{t}\right) \\
& \rho_{n f} \overline{u_{j}^{\prime} u_{i}^{\prime}} \text { and } \mu_{t} \text { are: } \\
& -\overline{u_{j}^{\prime} u_{i}^{\prime}} \rho_{n f}=\mu_{t}\left(\frac{\partial u_{i}}{\partial x_{j}}+\frac{\partial u_{j}}{\partial x_{i}}\right)-\frac{2}{3} \rho_{n f} k \delta_{i j}-\frac{2}{3} \mu_{t} \frac{\partial u_{k}}{\partial x_{k}} \delta_{i j} \\
& \mu_{t}=\rho_{n f} C_{\mu} k^{2} / \varepsilon
\end{aligned}
$$

$k, \varepsilon$ can be predicted as: 


$$
\begin{aligned}
& \frac{\partial}{\partial x_{j}}\left(\left(\frac{\mu_{t}}{\sigma_{k}}+\mu_{n f}\right) \frac{\partial k}{\partial x_{j}}\right)-\rho_{n f} \varepsilon+G_{k}=\frac{\partial}{\partial x_{i}}\left(u_{i} \rho_{n f} k\right), G_{k}=-\frac{\partial u_{j}}{\partial x_{i}} \rho_{n f} \overline{u_{j}^{\prime} u_{i}^{\prime}} \\
& \frac{\partial}{\partial x_{i}}\left(u_{i} \rho_{n f} \varepsilon\right)=\frac{\partial}{\partial x_{j}}\left(\left(\frac{\mu_{t}}{\sigma_{\varepsilon}}+\mu_{n f}\right) \frac{\partial \varepsilon}{\partial x_{j}}\right)+\frac{\varepsilon}{k} G_{k} C_{1 \varepsilon}-\rho_{n f} \frac{\varepsilon^{2}}{k} C_{2 \varepsilon} \\
& C_{1 \varepsilon}=1.42, C_{\mu}=0.0845, C_{2 \varepsilon}=1.68, \operatorname{Pr}_{t}=0.85, \sigma_{k}=1, \sigma_{\varepsilon}=1.3
\end{aligned}
$$

ANSYS Fluent software selected as simulation tool. k- $\varepsilon$ (RNG) model was chosen as turbulent model. Table 3 shows more details of setting.

$\rho_{n f},\left(\rho C_{p}\right)_{n f}, k_{n f}$ and $\mu_{n f}$ are:

$$
\begin{aligned}
& \rho_{n f}=\rho_{f}(1-\phi)+\rho_{s} \phi \\
& \left(\rho C_{p}\right)_{n f}=-(\phi-1)\left(\rho C_{p}\right)_{f}+\left(\rho C_{p}\right)_{s} \phi
\end{aligned}
$$

$$
\begin{aligned}
& \frac{k_{n f}}{k_{f}}=1+3 \frac{\phi\left(k_{p} / k_{f}-1\right)}{-\phi\left(k_{p} / k_{f}-1\right)+\left(2+k_{p} / k_{f}\right)}+5 \times 10^{4} g^{\prime}\left(\phi, T, d_{p}\right) \phi \rho_{f} c_{p, f} \sqrt{\frac{\kappa_{b} T}{\rho_{p} d_{p}}} \\
& g^{\prime}\left(\phi, T, d_{p}\right)=\left(a_{1}+a_{2} \operatorname{Ln}\left(d_{p}\right)+a_{5} \operatorname{Ln}\left(d_{p}\right)^{2}+a_{3} \operatorname{Ln}(\phi)+a_{4} \operatorname{Ln}(\phi) \ln \left(d_{p}\right)\right) \operatorname{Ln}(T) \\
& +\left(a_{6}+a_{7} \operatorname{Ln}\left(d_{p}\right)+a_{10} \operatorname{Ln}\left(d_{p}\right)^{2}+a_{8} \operatorname{Ln}(\phi)+a_{9} \ln \left(d_{p}\right) \operatorname{Ln}(\phi)\right), \\
& \frac{4 \times 10^{-8}}{d_{p}}=-1 / k_{p}+1 / k_{p, e f f} \\
& \frac{\mu_{n f}}{\mu_{f}}=\frac{k_{\text {Brownian }}}{\operatorname{Pr} k_{f}}+\frac{1}{(1-\phi)^{2.5}}
\end{aligned}
$$

Boundary conditions at $\mathrm{z}=0$ and $\mathrm{z}=900$ are:

$$
v_{i}=0, u_{i}=0, w_{i}=c t e, T_{i}=c t e, I=0.16(\operatorname{Re})^{\frac{-1}{8}}
$$




$$
\frac{\partial \mathrm{v}}{\partial \mathrm{z}}=\frac{\partial \mathrm{u}}{\partial \mathrm{z}}=\frac{\partial \mathrm{w}}{\partial \mathrm{z}}=0, \frac{\partial \mathrm{T}}{\partial \mathrm{z}}=0
$$

In this paper, the hydraulic diameter, $\mathrm{Re}, \mathrm{Nu}$, and $f$ can be defined as:

$$
\begin{aligned}
& D_{h}=\frac{4 A}{C} \\
& R e=\frac{\rho v_{i} D_{h}}{\mu} \\
& N u=\frac{h D_{h}}{k} \\
& f=\frac{\Delta p}{\frac{\rho v_{m}^{2}}{2} \frac{L}{D_{h}}}
\end{aligned}
$$

The entropy generation and Bejan number can be defined as [40]:

$$
\begin{aligned}
& S_{\text {gen,total }} \cong \frac{q^{\prime \prime 2} \mathrm{PD}_{\mathrm{h}} \mathrm{L}}{\mathrm{Nu} \cdot \mathrm{k} \cdot \mathrm{T}_{1} \mathrm{~T}_{2}}+\frac{8 \mathrm{rd} \mathrm{L}^{3} \mathrm{fL}}{\rho^{2} \mathrm{~T}_{\mathrm{avg}} \mathrm{D}_{\mathrm{h}}{ }^{3} \mathrm{P}^{2}}=S_{\text {gen,th }}+S_{\text {gen }, f}, \\
& \mathrm{~T}_{\text {avg }}=\frac{\left(\mathrm{T}_{1}-\mathrm{T}_{2}\right)}{\ln \left(\mathrm{T}_{1} / \mathrm{T}_{2}\right)} \\
& \mathrm{Be}=\frac{S_{\text {gen,th }}}{S_{\text {gen }, f}+S_{\text {gen }, \text { th }}}
\end{aligned}
$$

Outputs should not depend on mesh size. Table 4 shows various meshes for one case as an example. According to this table, the grid size of 1378654 cells is chosen for numerical modeling. The value of $\mathrm{y}^{+}$parameter should be less than 5 for our selected model (see table 5) to satisfy the limitation of k- $\varepsilon$ (Enhanced wall treatment) model $\left(Y^{+}<5\right)$. To verify the present code, local convective coefficients are verified with previous published article [41]. Fig. 3 demonstrated correctness of this code. 


\section{Results and discussion}

$\mathrm{CuO}$-water turbulent forced convection inside a pipe with turbulator is studied. Entropy generations of nanofluid are investigated and obtained result are shown as contours and related correlations. Brownian motion impact on thermal conductivity of $\mathrm{CuO}$-water is taken into account. Influence pitch ratio $(P R=5$ to 15$)$, Reynolds number $(R e=5000$ to 20000$)$ and height ratio $(B R=0.3$ to 0.5$)$ on nanofluid entropy generation are illustrated.

Fig. 4 depicts the stream tracer contours for various values of active parameters. Using lower pitch ratio leads to better nanofluid mixing due to stronger secondary flows. Besides, similar behavior is observed for Reynolds number and height ratio. As Reynolds number augments, pressure loss augments and temperature boundary layer thickness reduces. Increasing height ratio and decreasing pitch ratio lead to higher temperature gradient but with cost of higher pressure loss.

Related formulas for entropy generation and Bejan number are:

$$
\begin{aligned}
& S_{\text {gen }, f}^{*}=10^{5} \times S_{\text {gen }, f}=0.91-0.33 P R+0.26 B R+1.55 \mathrm{Re} \\
& -0.17(P R)(B R)-0.19(P R)(\operatorname{Re})+0.32(\operatorname{Re})(B R)+0.73 \operatorname{Re}^{2} \\
& S_{\text {gen }, \text { th }}=0.032+1.8 \times 10^{-3} P R-1.3 \times 10^{-3} B R-0.022 \mathrm{Re} \\
& +6 \times 10^{-4}(P R)(B R)-8.54 \times 10^{-4}(P R)(\mathrm{Re})+5.4 \times 10^{-4}(\mathrm{Re})(B R)+0.014 \mathrm{Re}^{2} \\
& S_{\text {gen,total }}=0.032+1.81 \times 10^{-3} \mathrm{PR}-1.3 \times 10^{-3} \mathrm{BR}-0.022 \mathrm{Re} \\
& +5.9 \times 10^{-4}(P R)(B R)-8.58 \times 10^{-4}(P R)(\operatorname{Re})+5.5 \times 10^{-4}(\operatorname{Re})(B R)+0.014 \operatorname{Re}^{2}
\end{aligned}
$$




$$
\begin{aligned}
& \mathrm{Be}=1+1.61 \times 10^{-3} P R-1.3 \times 10^{-4} B R-7.04 \times 10^{-4} \mathrm{Re} \\
& +9 \times 10^{-5}(P R)(B R)+2.1 \times 10^{-4}(P R)(\mathrm{Re})-1.7 \times 10^{-4}(\mathrm{Re})(B R)-4.42 \times 10^{-4} \mathrm{Re}^{2}
\end{aligned}
$$

Effects of Reynolds number, pitch ratio and height ratio on $S_{g e n, f}, S_{\text {gen, }, \mathrm{h}}, S_{\text {gen,total }}$ and Bejan number are shown in Figs. 5, 6, 7 and 8. $S_{\text {gen,f }}$ is an increasing function of Reynolds number and height ratio. This is due to increase in velocity gradient with increase if Re, BR. Opposite behavior is reported for $S_{\text {gen }, \text { th }}$. Effect of active parameters on $S_{\text {gen,total }}$ is similar to those of $S_{\text {gen,th }}$ because $S_{\text {gen }, f}$ is obtanied to be too lower than $S_{g e n, t h}$. The ratio of the thermal and total entropy generation rates has been introduced as Bejan number. Bejan number at low Reynolds number is close to 1 because the thermal entropy generation is prominent. Bejan number enhances with augment of pitch ratio. Also, it decreases with rise of Reynolds number and height ratio.

\section{Conclusion}

In this article, heat exchanger with twisted tape turbulators is simulated via FVM. Working fluid is water based nanofluid and experimental correlations are used to estimate its properties. Entropy generation and Bejan number are presented as suitable formulas according to results. Results show that Bejan number can enhance with augment of pitch ratio. Total entropy generation has reverse relationship with Nusselt number. 
Acknowledgements: This research was supported by the National Sciences Foundation of China (NSFC) (No. U1610109), Yingcai Project of CUMT (YC2017001), PAPD and UOW Vice-Chancellor's Postdoctoral Research Fellowship 


\section{References}

[1] Mohsan Hassan, Ahmad Zeeshan, Aaqib Majeed, Rahmat Ellahi, Journal of Magnetism and Magnetic Materials443 (2017) 36-44.

[2] C.S.K. Raju, N. Sandeep, A. Malvandi, Journal of Molecular Liquids 221 (2016) $108-115$

[3] M. Sheikholeslami, M. Jafaryar, Zhixiong Li, International Journal of Heat and Mass Transfer 124 (2018) 980-989

[4] R. Ellahi, A. Zeeshan, M. Hassan, Mechanics of Advanced Materials and Structures 24.15 (2017): 1231-1238

[5] A. Mwesigye, T. Bello-Ochende, J. P. Meyer, International Journal of Thermal Sciences 99 (2016) 238-257.

[6] Mohsen Sheikholeslami, Journal of the Taiwan Institute of Chemical Engineers 86 (2018) 25-41

[7] A. R. S. Suri, A. Kumar, R. Maithani, Chemical Engineering and Processing: Process Intensification 116, (2017) 76-96.

[8] Obaid Ullah Mehmood, Muhammad Muddassar Maskeen, Ahmad Zeeshan, Advances in Mechanical Engineering 9.11 (2017): 1687814017735282.

[9] M.M. Bhatti, M. Sheikholeslami, A. Zeeshan, Entropy 19.9 (2017): 481

[10] S. U. Rehman, A. Zeeshan, A. Majeed, M. B. Arain, Journal of Magnetics 22.3 (2017) 472-477.

[11] R. Ahmad, M. Mustafa, Journal of Molecular Liquids, 220 (2016) 635-641. 
[12] M. Sheikholeslami, A. Zeeshan, International Journal of Hydrogen Energy, 42 (22) (2017) 15393-15402

[13] K. Ganesh Kumar, Rizwan-ul-Haq, N.G. Rudraswamy, B.J. Gireesha, Results in Physics, 7 (2017) 3465-3471.

[14] O.D. Makinde, F. Mabood, W.A. Khan, M.S. Tshehla, Journal of Molecular Liquids, 219 (2016) 624-630.

[15] Rizwan Ul Haq, Irfan Rashid, Z.H. Khan, Journal of Molecular Liquids, 243 (2017) 682-688.

[16] C.S. K. Raju, N. Sandeep, European Physical Journal Plus, 131 (2016) 267.

[17] Nor Athirah Mohd Zin, Ilyas Khan, Sharidan Shafie, Ali Saleh Alshomrani, Results in Physics, 7 (2017) 288-309

[18] Ali J. Chamkha, M.M. Abd El-Aziz and S.E. Ahmed, Int. J Energy and Technology2(4) (2010) $1-7$

[19] Sun Fengrui, Yao Yuedong, Li Xiangfang, Li Guozhen, Chen Zhili, Chang Yucui, Cao Meng, Han Song, Chaohui Lv, Feng Dong, Sun Zheng, Journal of Petroleum Science and Engineering, 2018, 162, 460-468.

[20] M. Sheikholeslami, Journal of Molecular Liquids 249 (2018) 739-746

[21] Mohsen Sheikholeslami, Journal of Molecular Liquids 249 (2018) 921-929

[22] M. Sheikholeslami, Houman B. Rokni, International Journal of Heat and Mass Transfer 118 (2018) 823-831

[23] M. Sheikholeslami, Journal of Molecular Liquids 234 (2017) 364-374 
[24] M. Sheikholeslami, Journal of Molecular Liquids 231 (2017) 555-565

[25] Mohsen Sheikholeslami, Journal of Molecular Liquids 229 (2017) 137-147

[26] Mohsen Sheikholeslami, Journal of Molecular Liquids 225 (2017) 903-912

[27] Mikhail A. Sheremet, Ioan Pop, Natalia C. Roşca, Journal of the Taiwan Institute of Chemical Engineers, Volume 61, April 2016, Pages 211-222

[28] Fengrui Sun, Yuedong Yao, Xiangfang Li, Guozhen Li, Qing Liu, Song Han, Yunjian Zhou, Journal of Petroleum Science and Engineering, 2018, 164, 655-662

[29] Kashif Ali Abro, Ilyas Khan, Chinese Journal of Physics, 55 (2017) 1583-1595

[30] M. Sheikholeslami, Journal of Molecular Liquids 259 (2018) 424-438

[31] M. Sheikholeslami, S.A. Shehzad, International Journal of Heat and Mass Transfer 122 (2018) 1264-1271

[32] M. Sheikholeslami, Houman B. Rokni, Journal of Molecular Liquids 254 (2018) $446-462$

[33] M. Sheikholeslami, Houman B. Rokni, Physics of Fluids, Volume 30, Issue 1, 10.1063/1.5012517, https://doi.org/10.1063/1.5012517

[34] M. Sheikholeslami, Journal of Molecular Liquids 249 (2018) 1212-1221

[35] Tasawar Hayat, Taseer Muhammad, Sabir Ali Shehzad, Ahmed Alsaedi, Computer Methods in Applied Mechanics and Engineering, 315 (2017) 467-477

[36] Syed Tauseef Mohyud-Din, Umar Khan, Naveed Ahmed, Muhammad Mehdi Rashidi 
Propulsion and Power Research, 7 (2018) 72-77

[37] Naveed Ahmed, Adnan, Umar Khan, Syed Tauseef Mohyud-Din, International Journal of Thermal Sciences 121 (2017) 182-191

[38] M. Sheikholeslami, A. Zeeshan, Computer Methods in Applied Mechanics and Engineering, 320 (2017) 68-81

[39] Mohsen Sheikholeslami, Davood Domiri Ganji, M. Younus Javed, R. Ellahi, Journal of Magnetism and Magnetic Materials 374 (2015) 36-43.

[40] E. B. Ratts, A. G. Raut, Journal of Heat Transfer 126 (2004) 656-659.

[41] D. Kim, Y. Kwon, Y. Cho, C. Li, S. Cheong, Y. Hwang, J. Lee, D. Hong, S. Moona, Current Applied Physics 9 (2009) 119-123. 


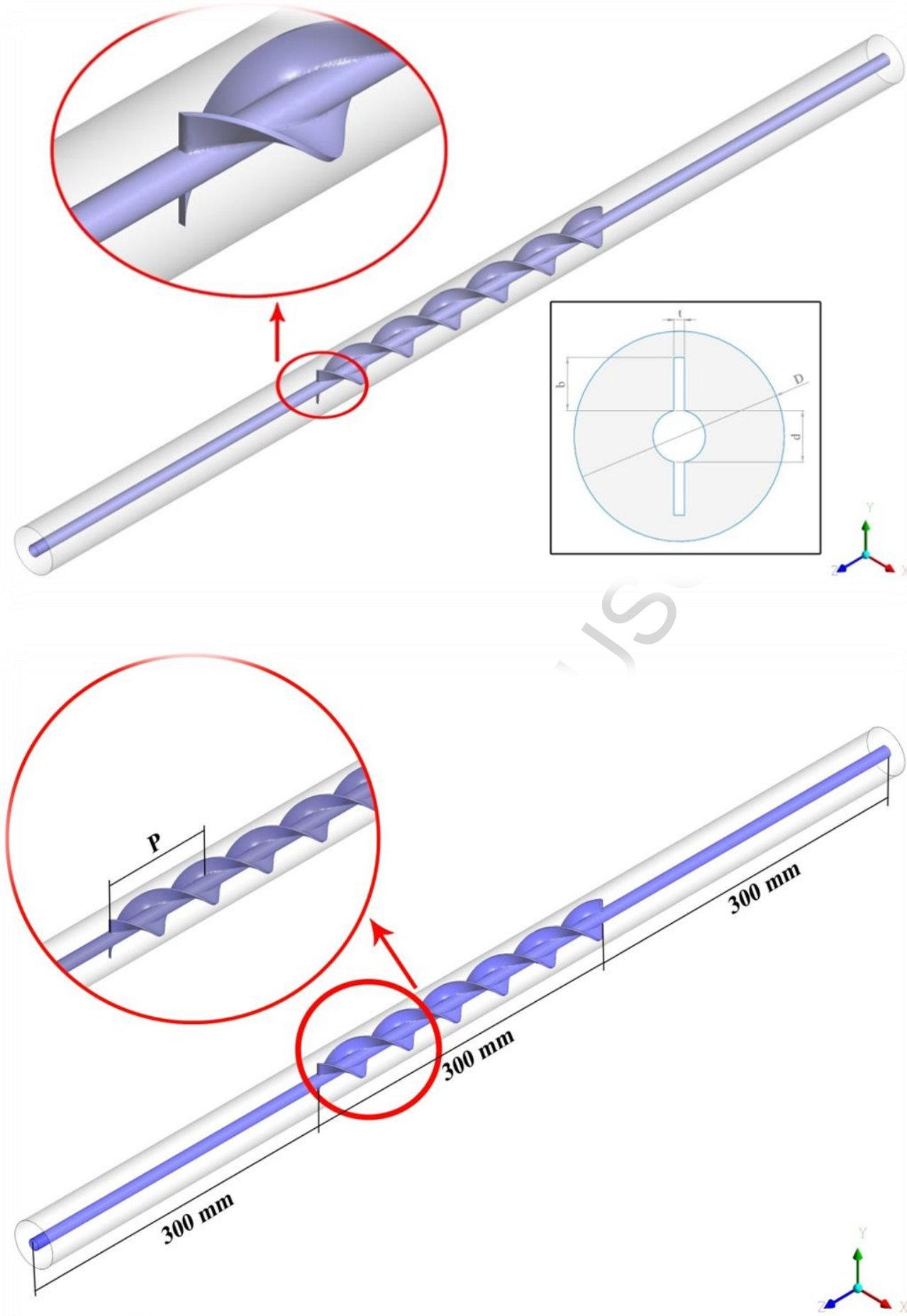

Fig 1. Geometry of the problem. 

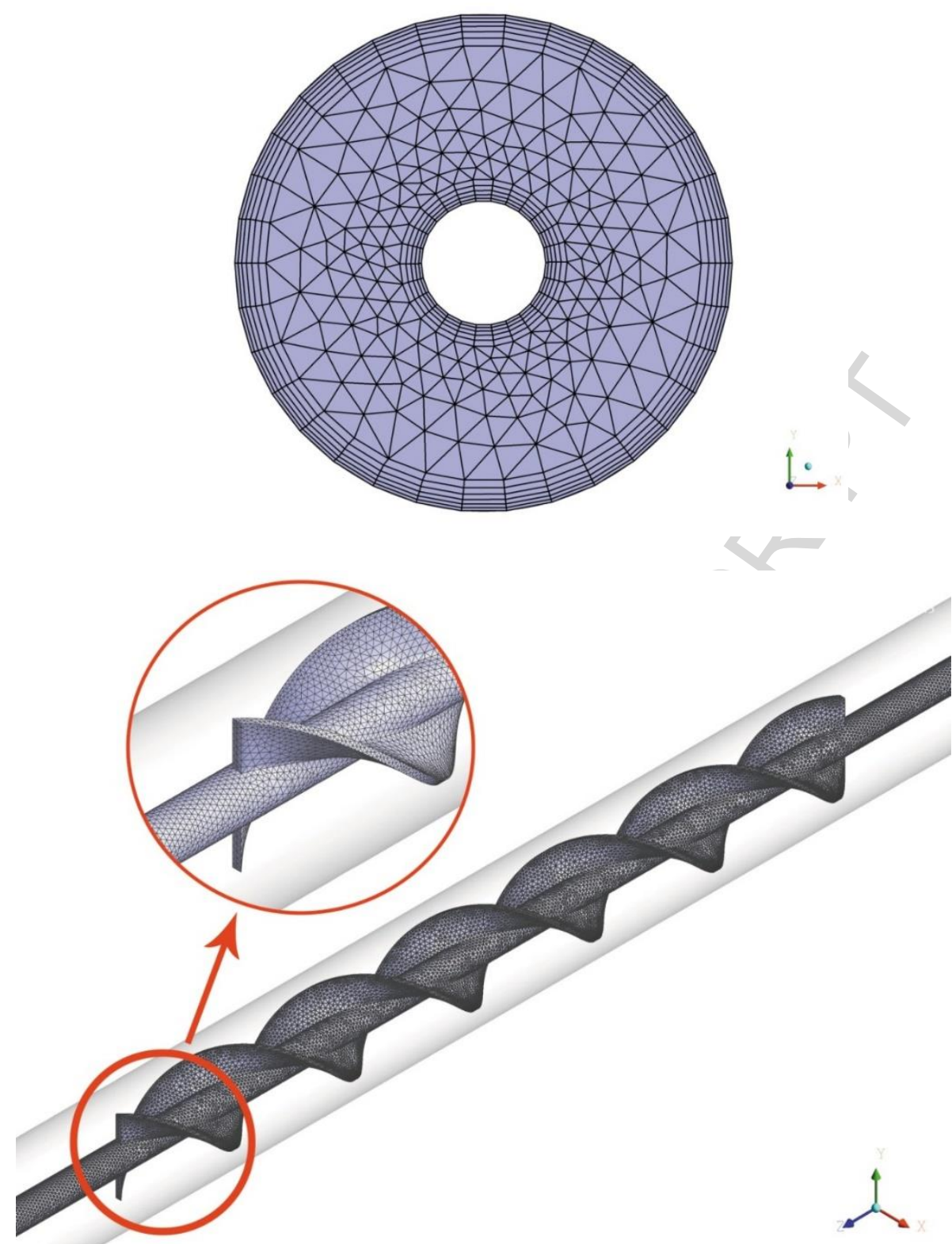

Fig. 2. Detail view of computational mesh 


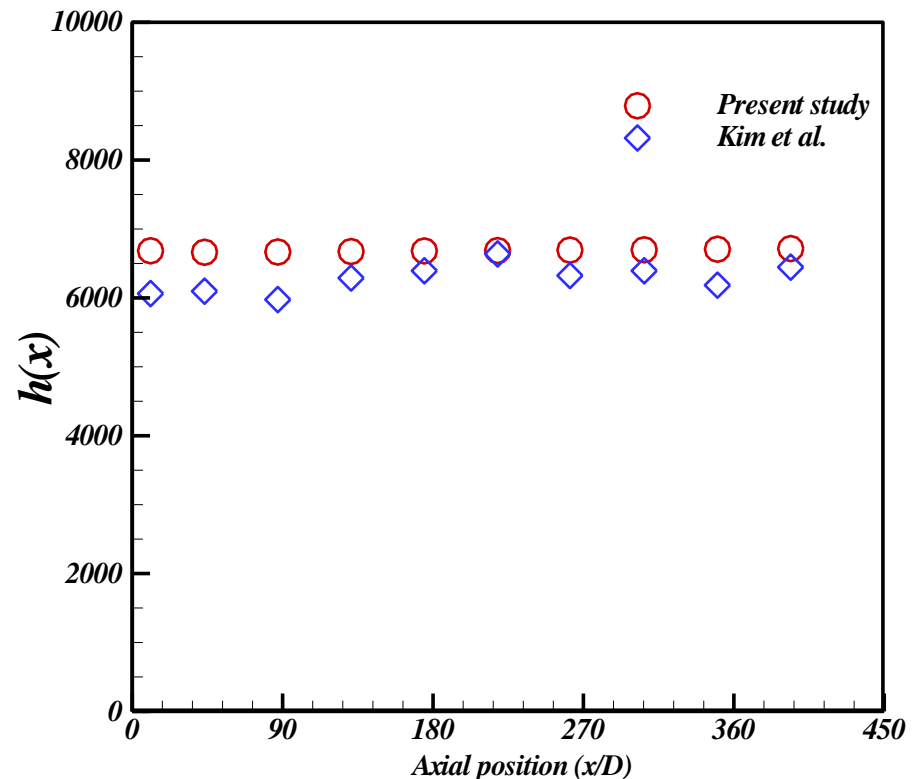

Fig.3. Comparison of Local convective heat transfer coefficient between the present result and previous work [24]. 


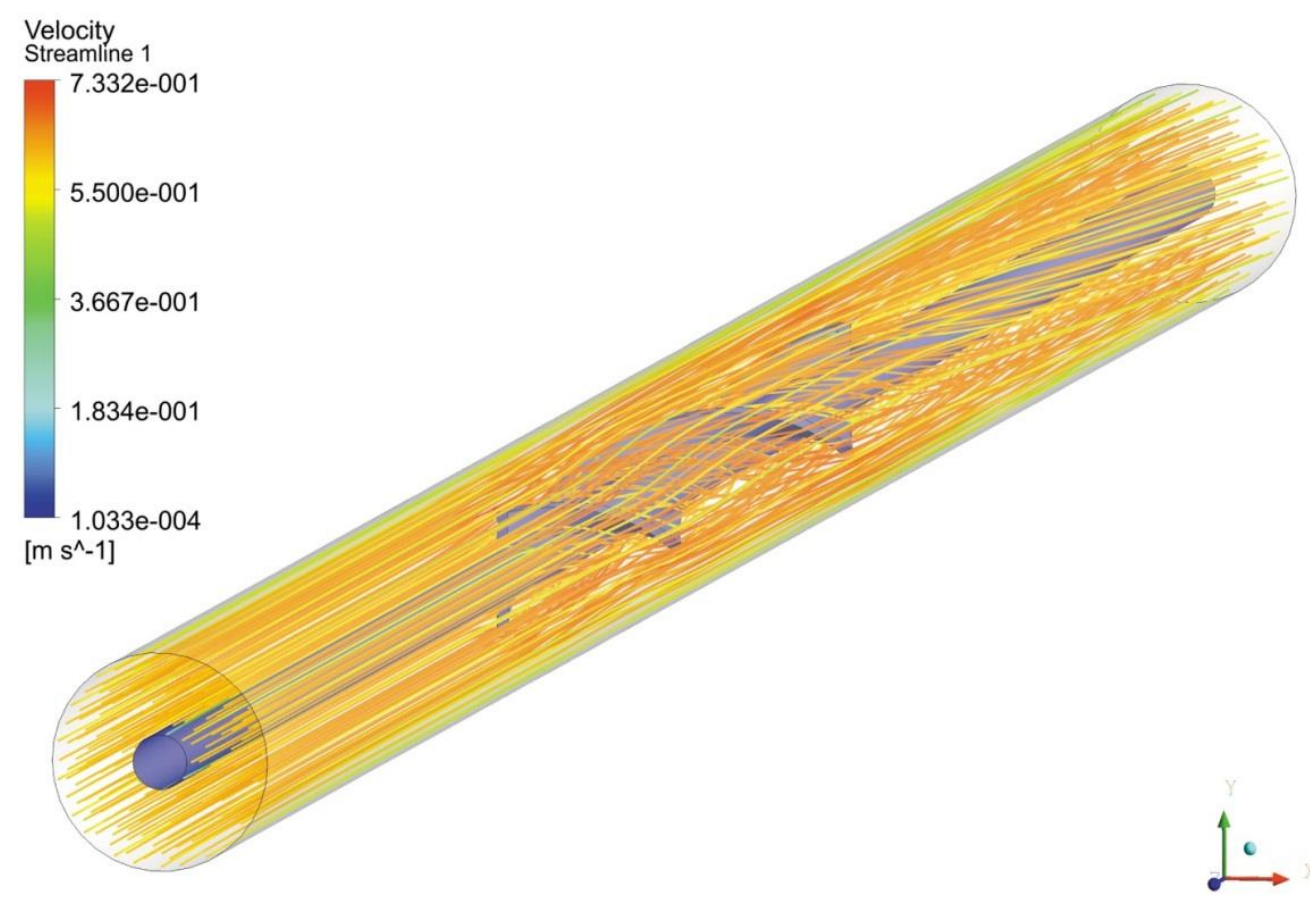

$\mathrm{PR}=15, \mathrm{BR}=0.3$

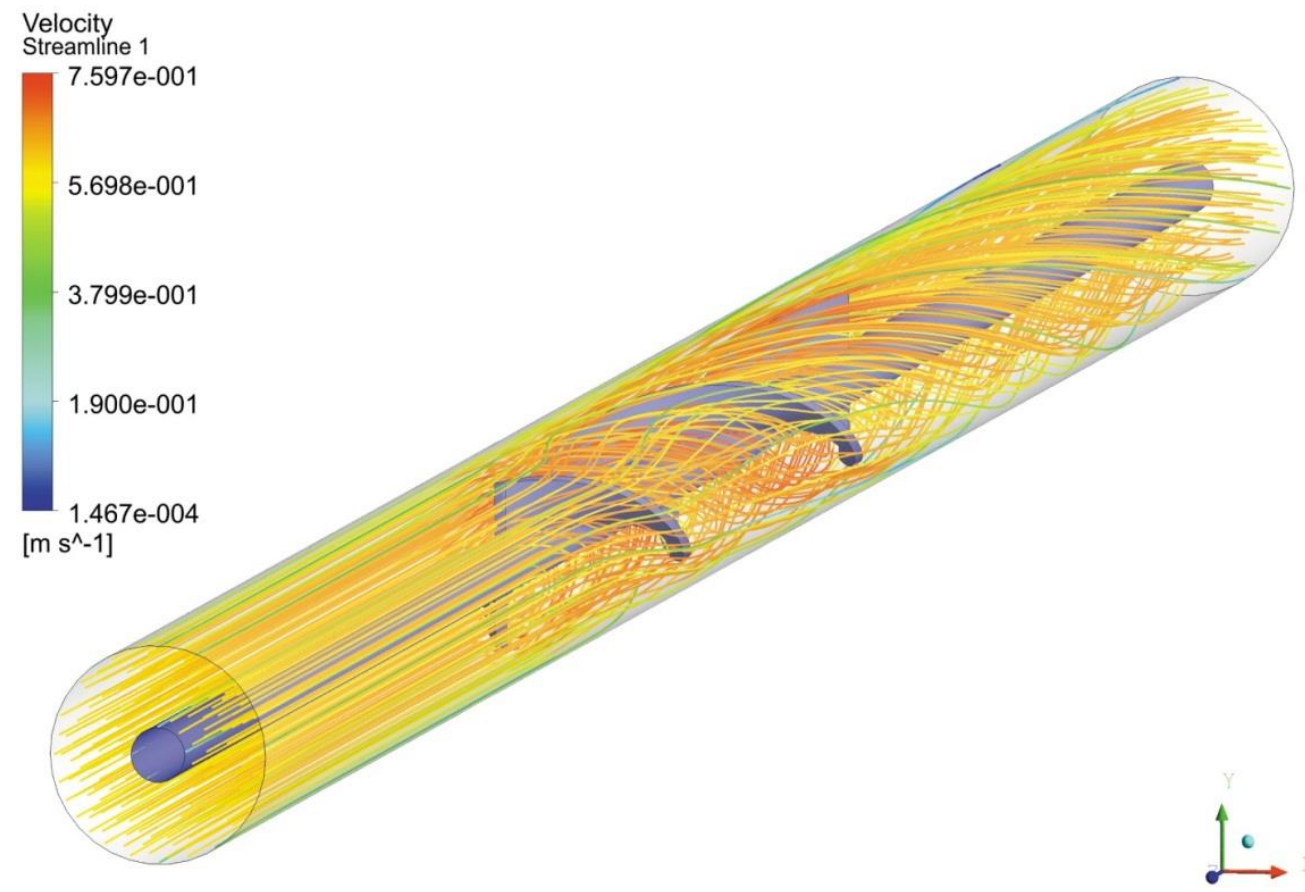

$\mathrm{PR}=15, \mathrm{BR}=0.5$ 


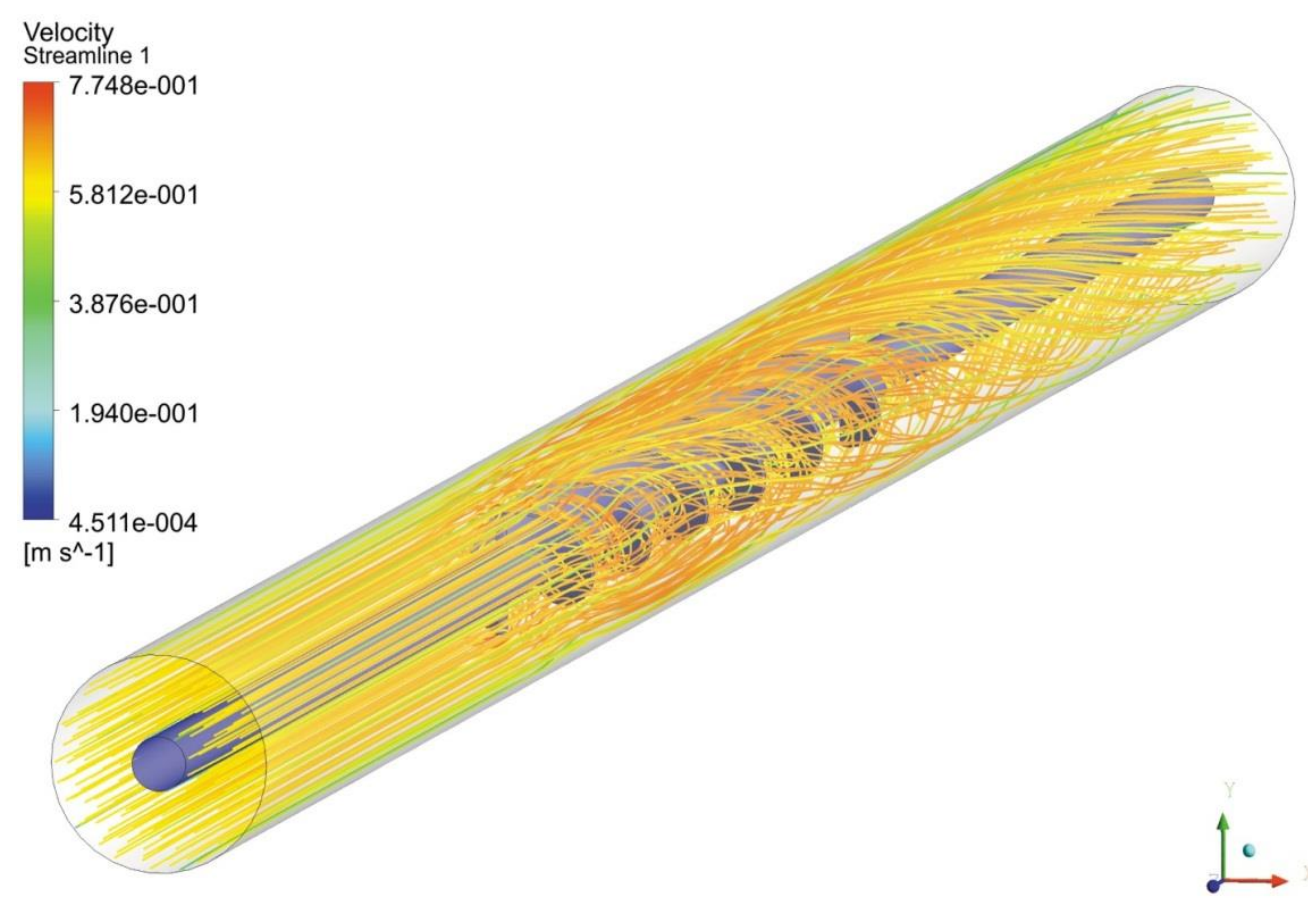

$\mathrm{PR}=5, \mathrm{BR}=0.3$

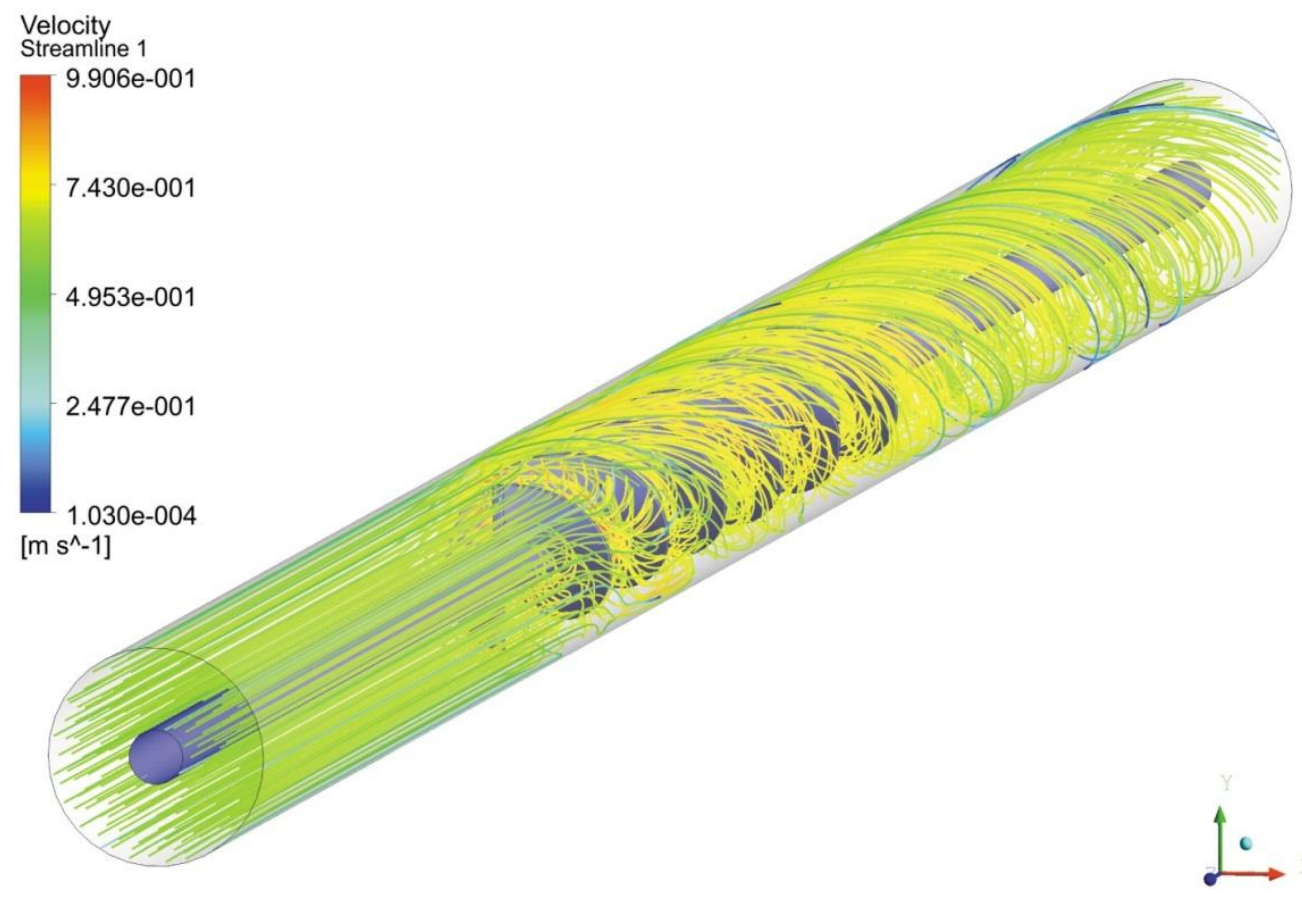

$\mathrm{PR}=5, \mathrm{BR}=0.5$

Fig. 4. Stream tracer contours when $\mathrm{Re}=20000$ 


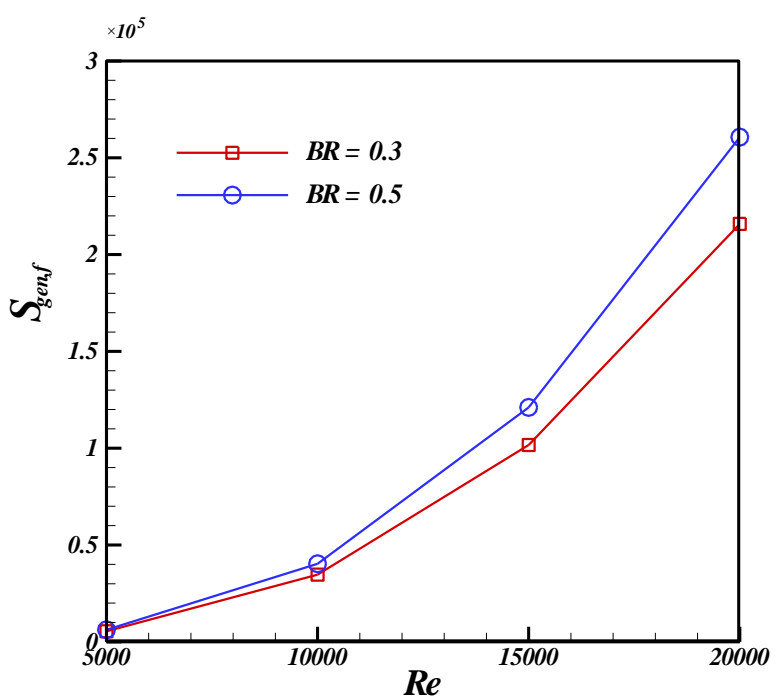

$P R=15$

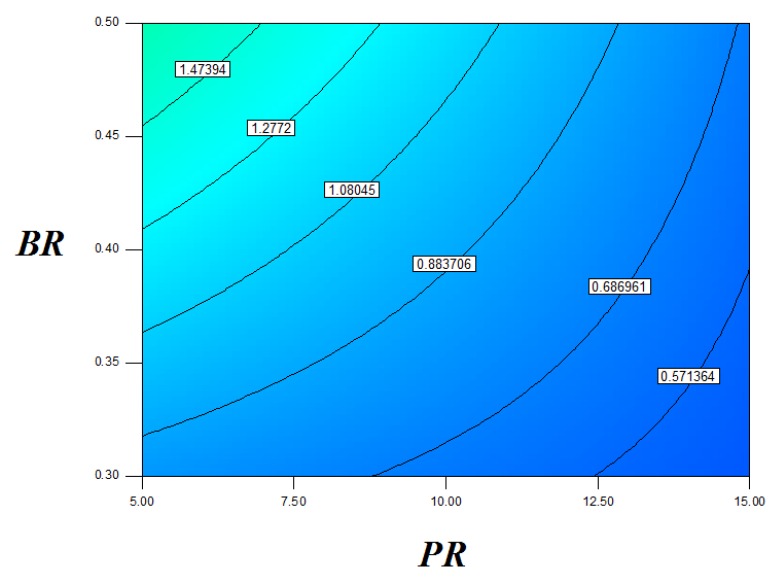

$\operatorname{Re}=10250$

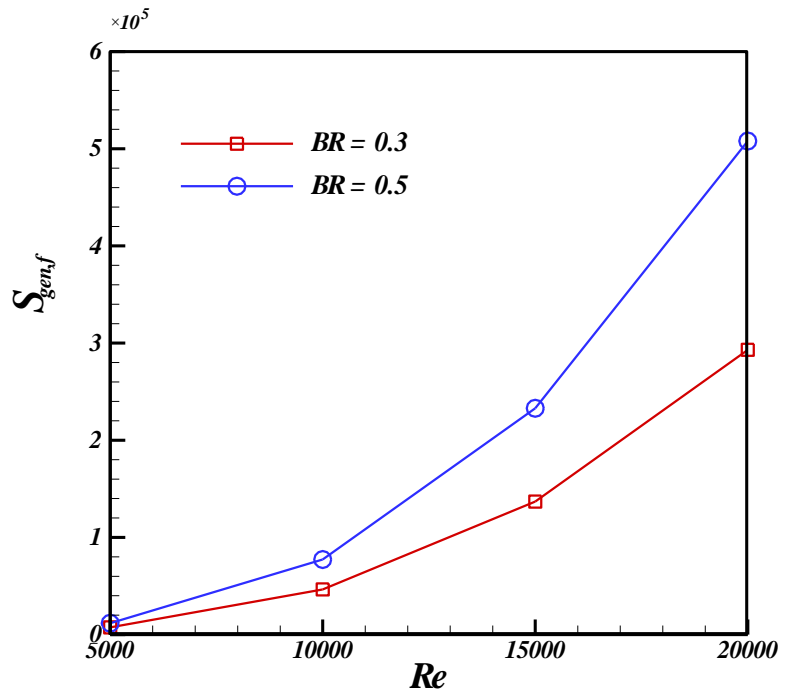

$P R=5$

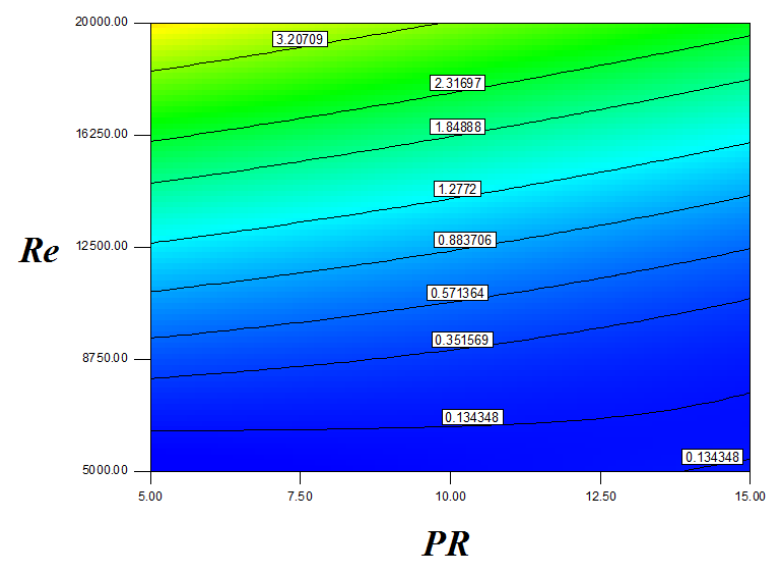

$B R=0.4$

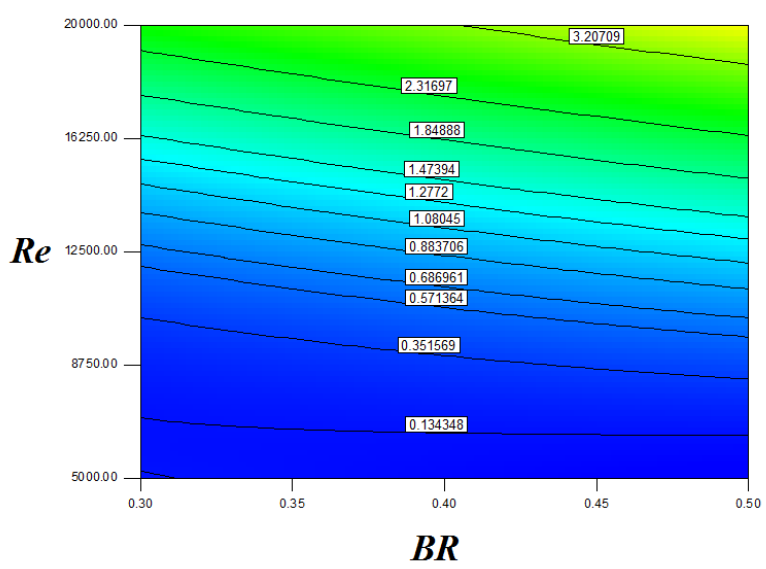

$P R=10$ 

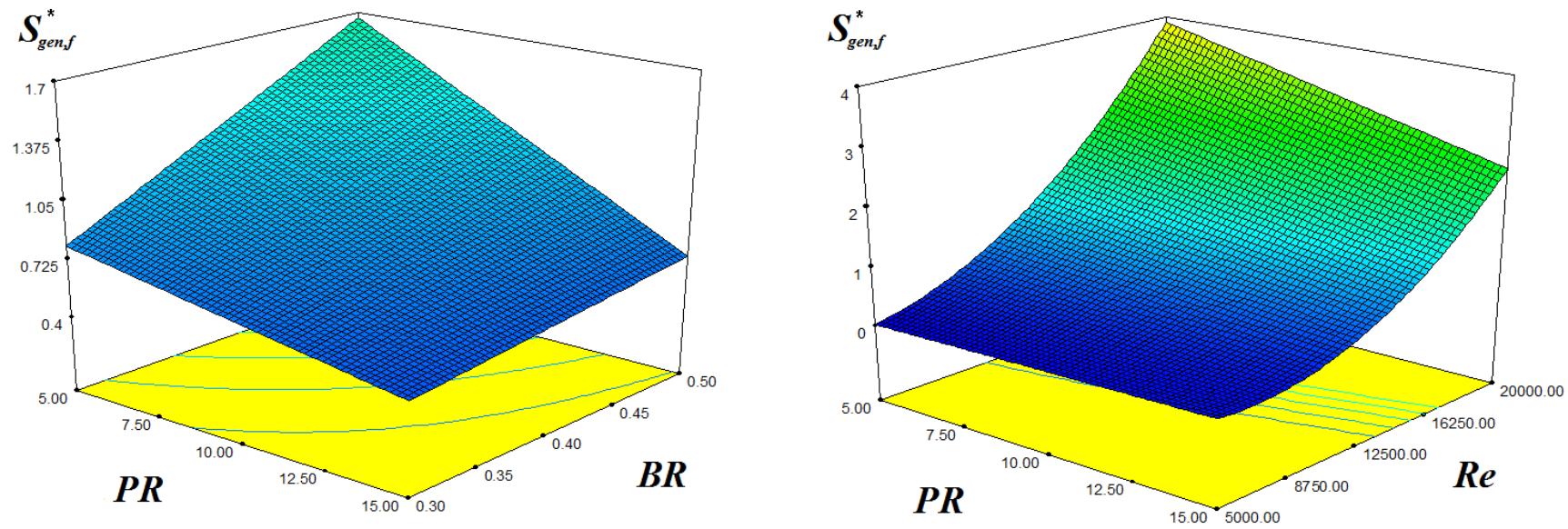

$$
\operatorname{Re}=10250
$$

$$
B R=0.4
$$

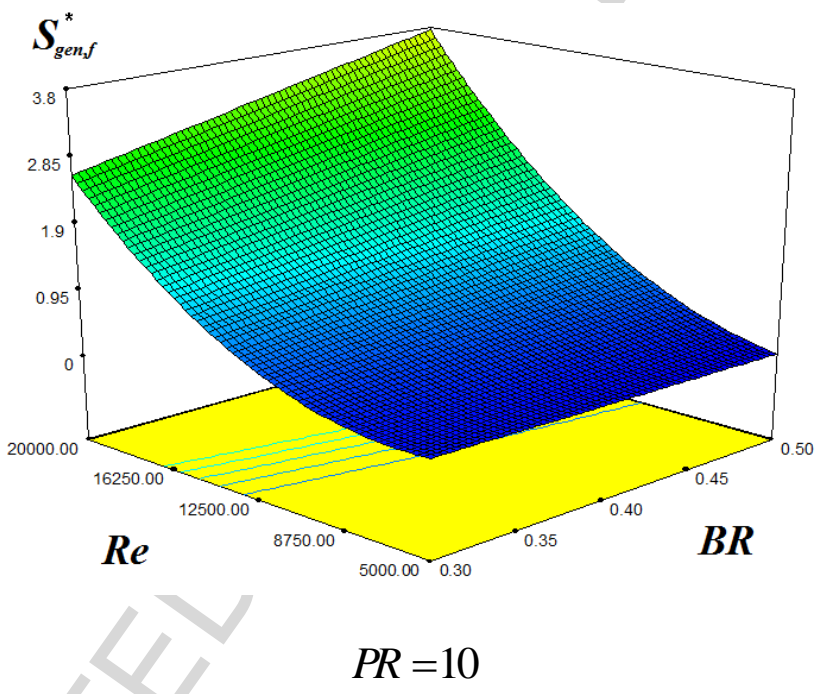

Fig. 5. Effect of Re, PR and BR on $S_{g e n, f}$ 


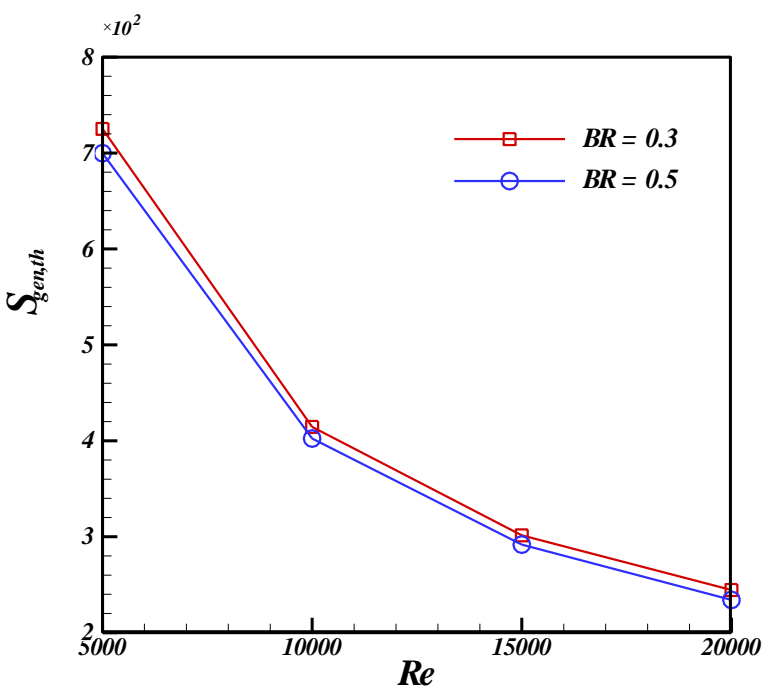

$P R=15$

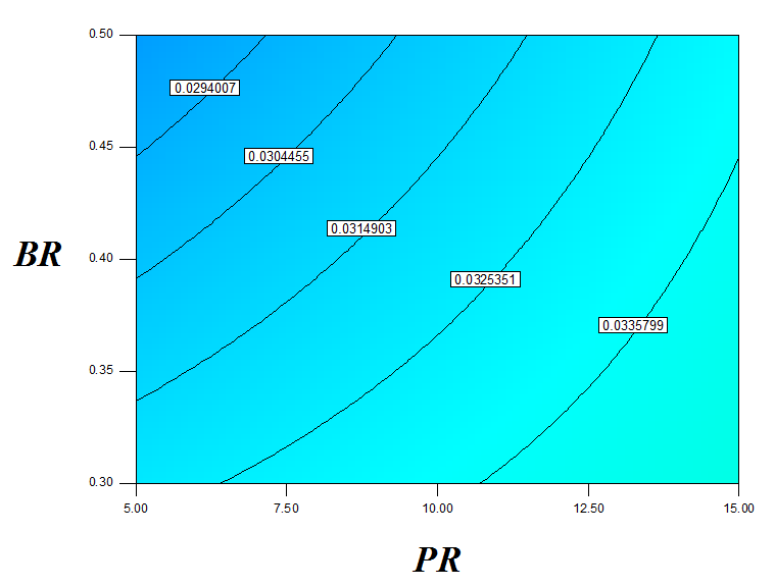

$\operatorname{Re}=10250$

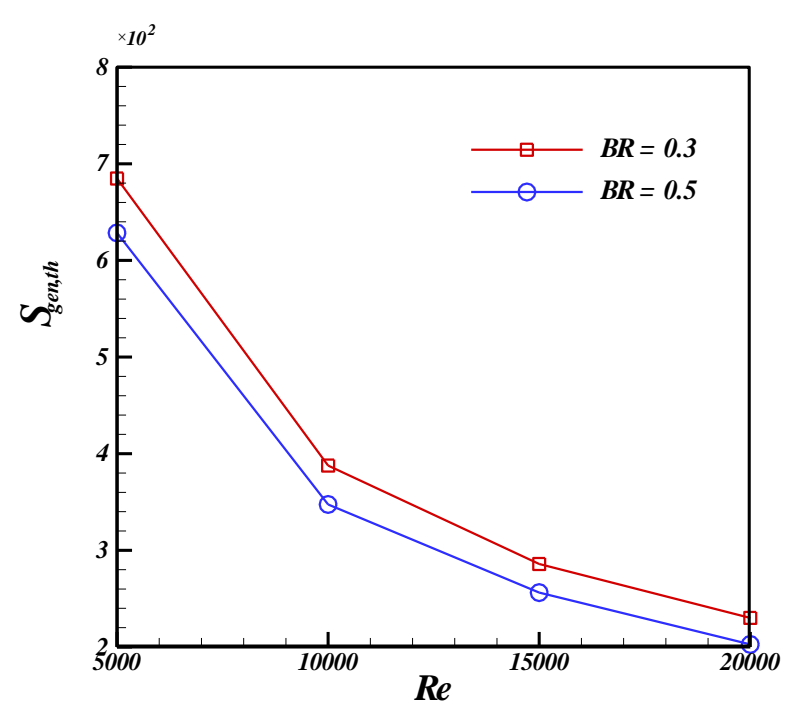

$P R=5$

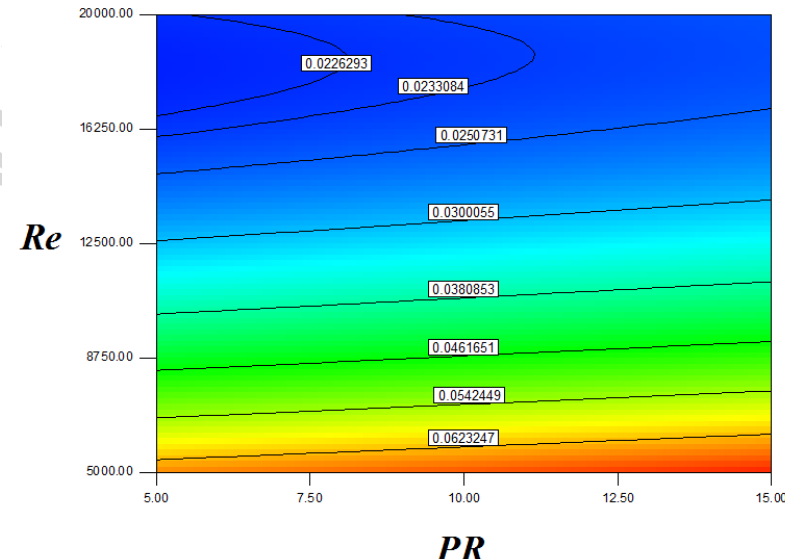

$B R=0.4$

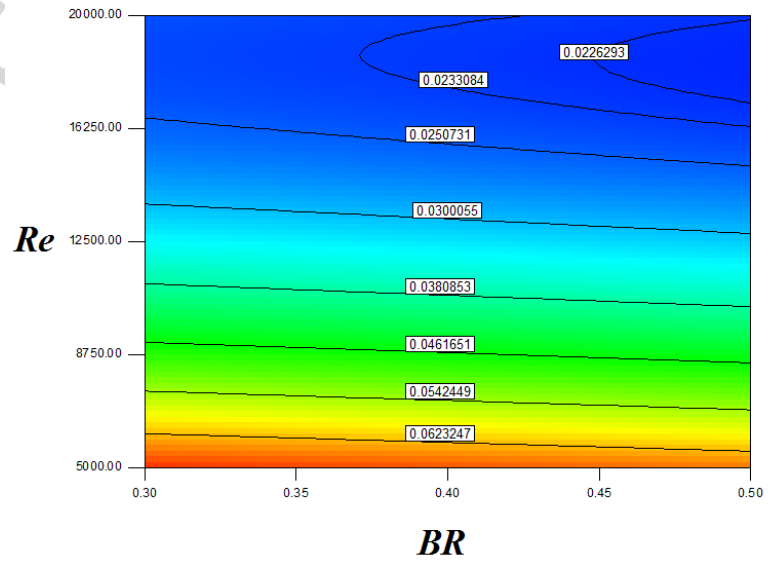

$P R=10$ 

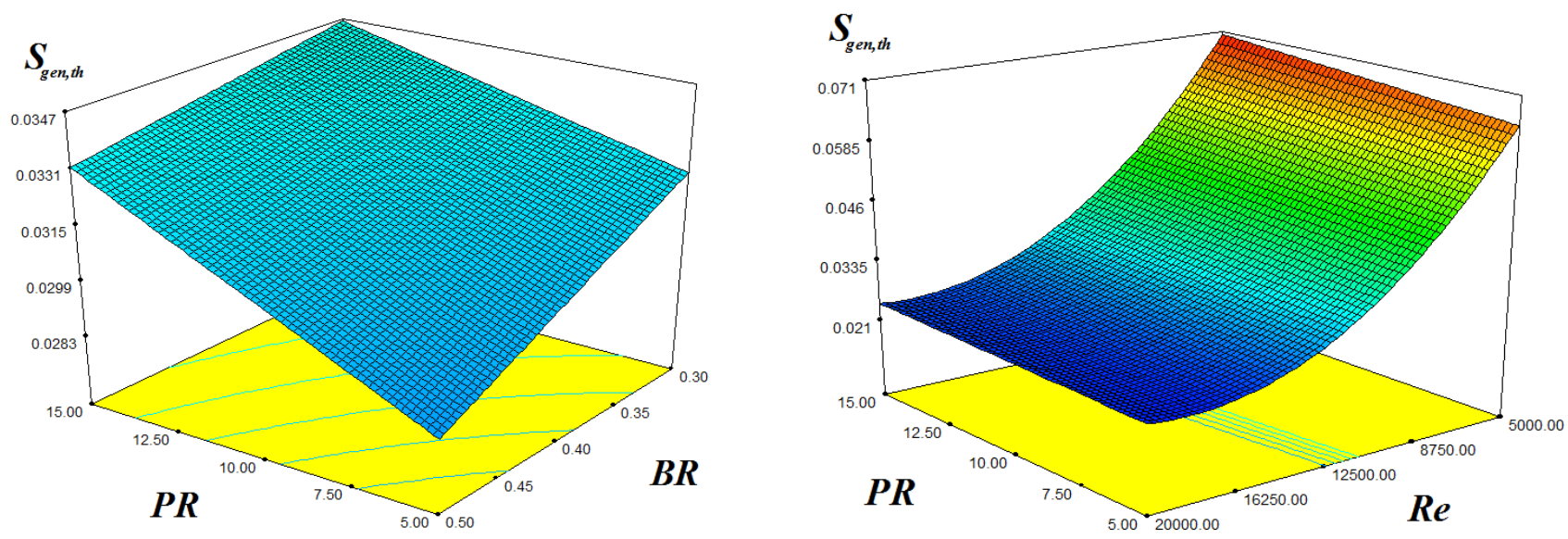

$\mathrm{Re}=10250$

$B R=0.4$

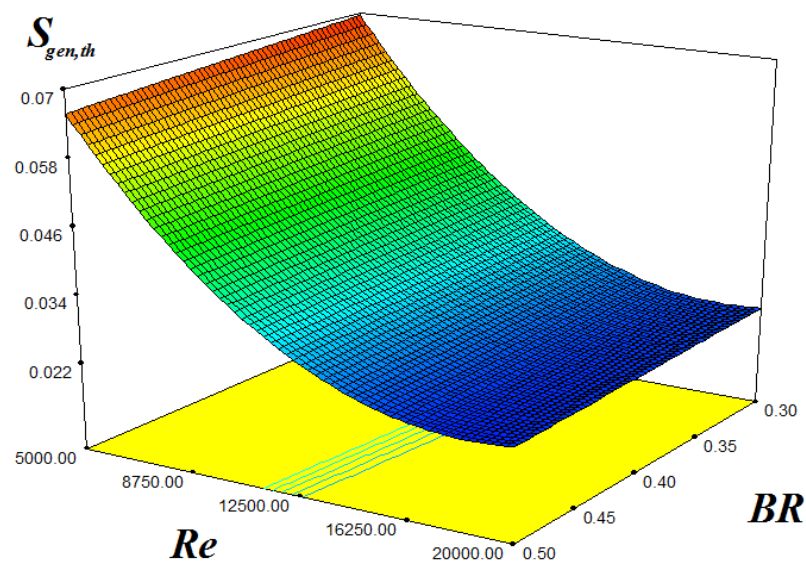

$$
P R=10
$$

Fig. 6. Effect of Re, PR and BR on $S_{g e n, t h}$ 


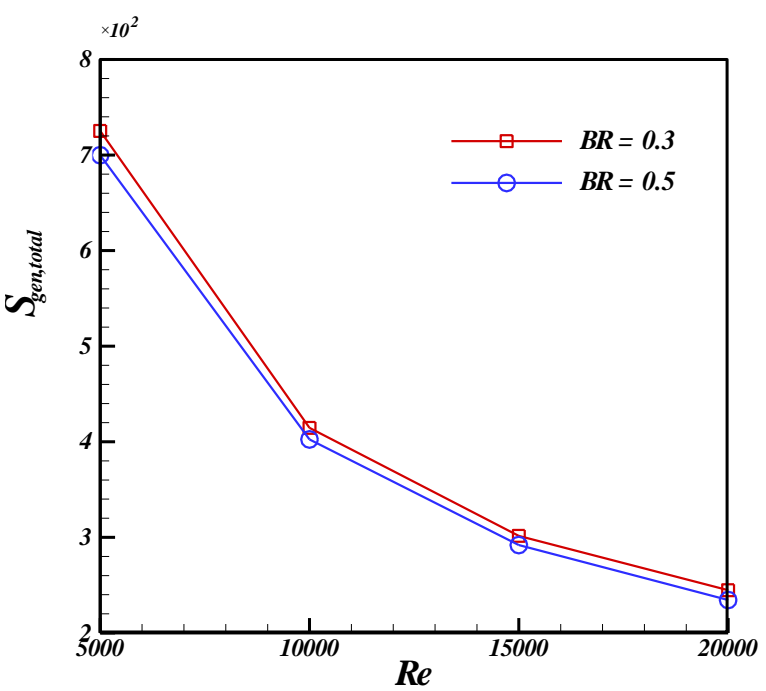

$P R=15$

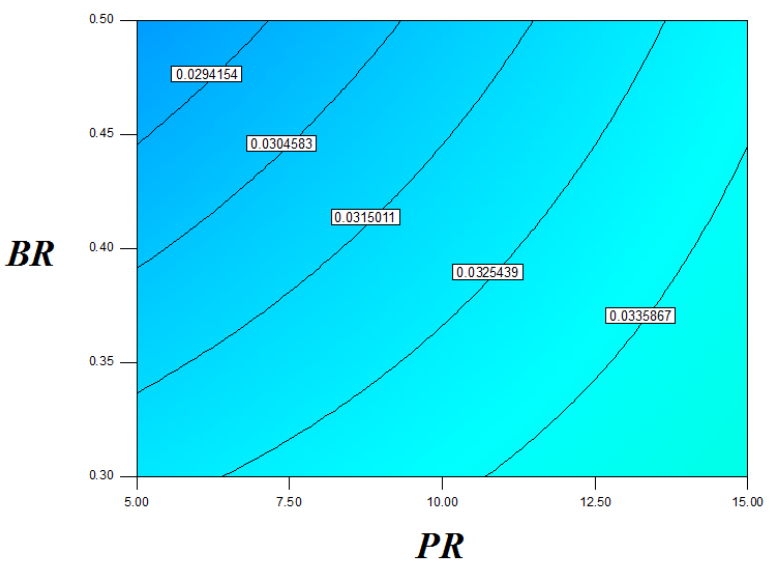

$\mathrm{Re}=10250$

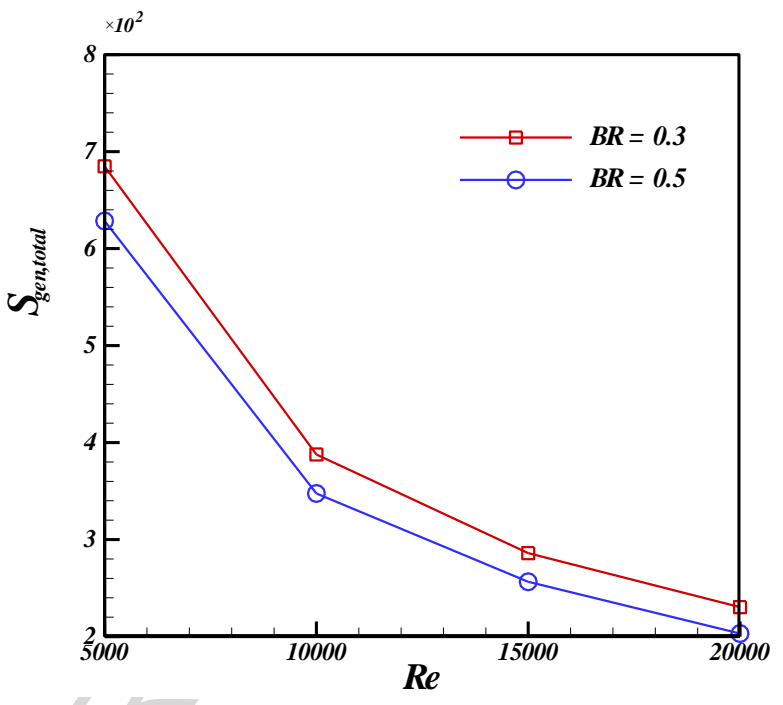

$P R=5$

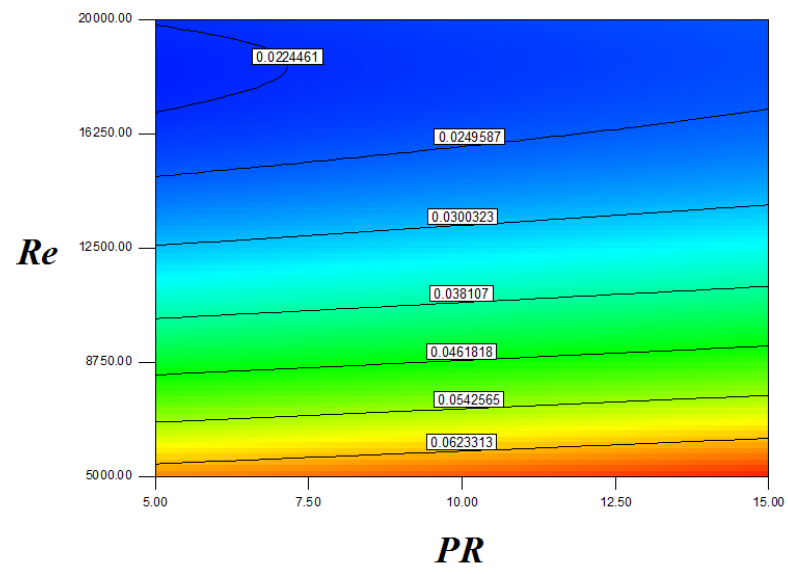

$B R=0.4$

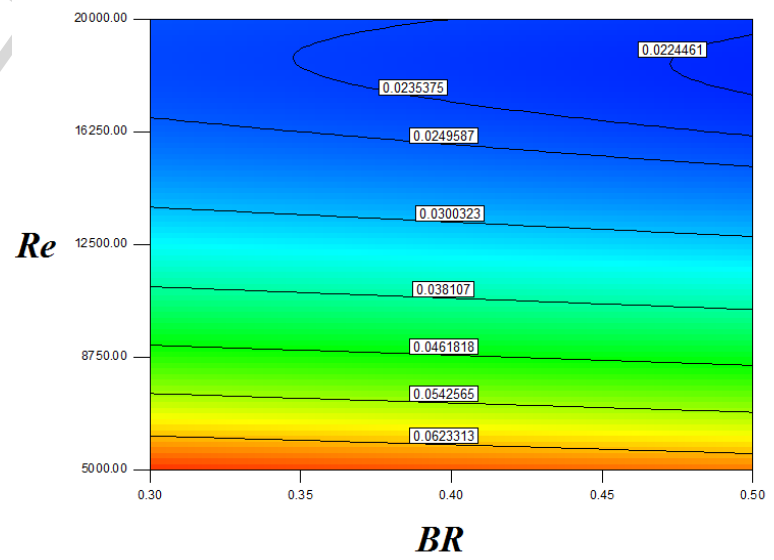

$P R=10$ 


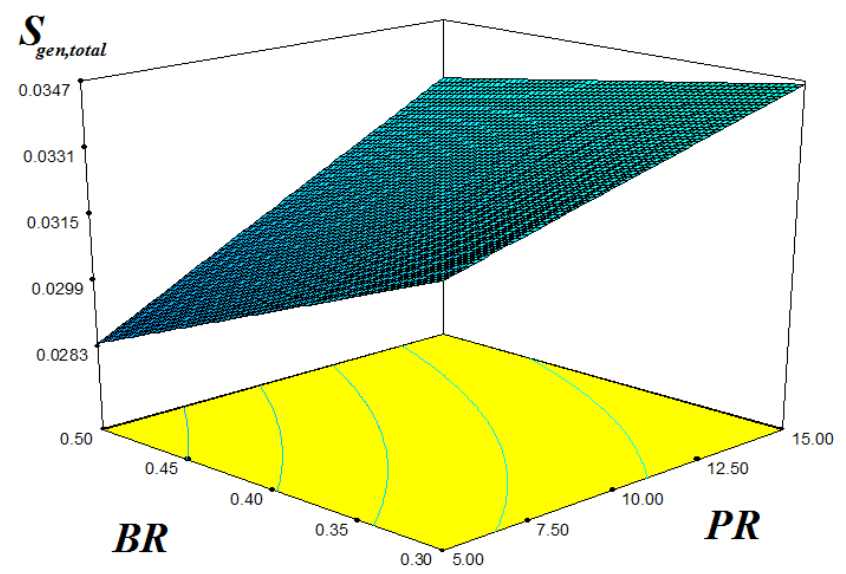

$\operatorname{Re}=10250$

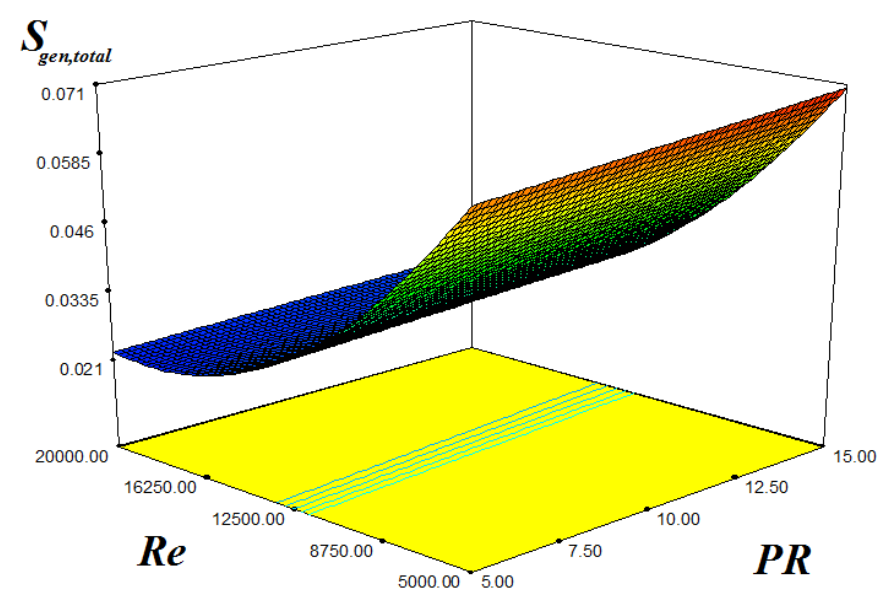

$B R=0.4$

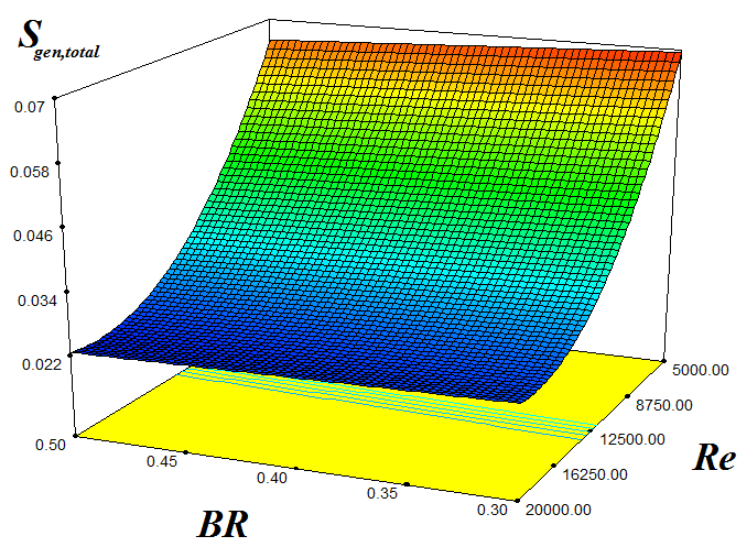

$P R=10$

Fig. 7. Effect of Re, PR and BR on $S_{\text {gen,total }}$ 


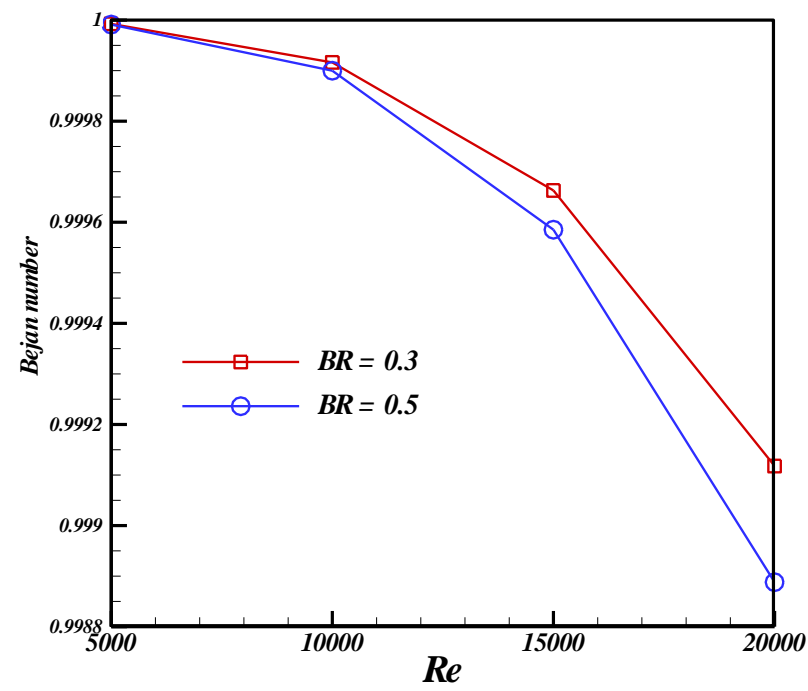

$P R=15$

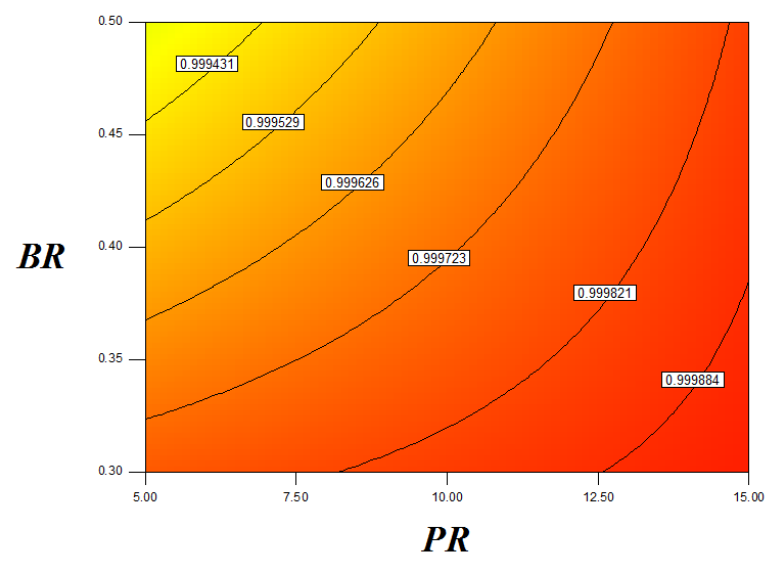

$\operatorname{Re}=10250$

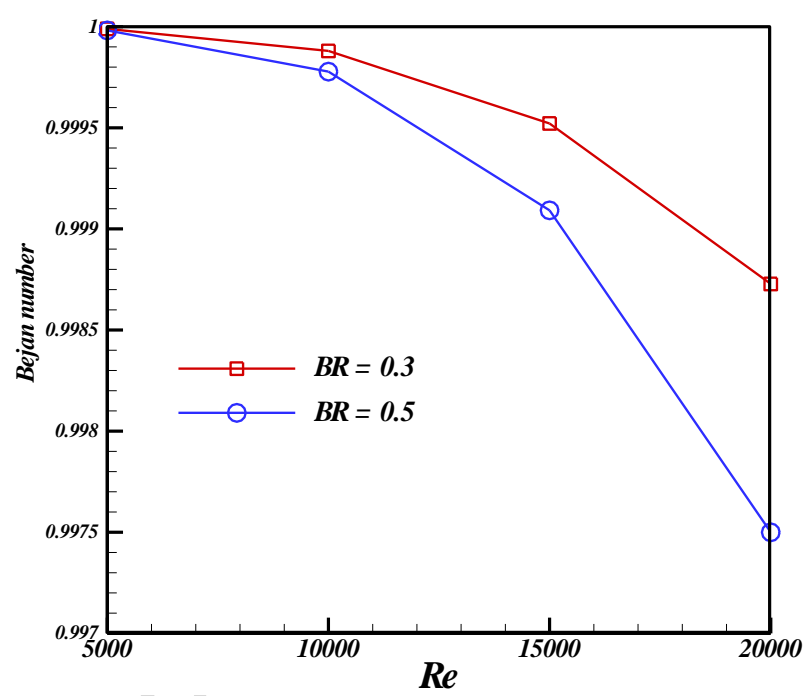

$\mathrm{PR}=5$

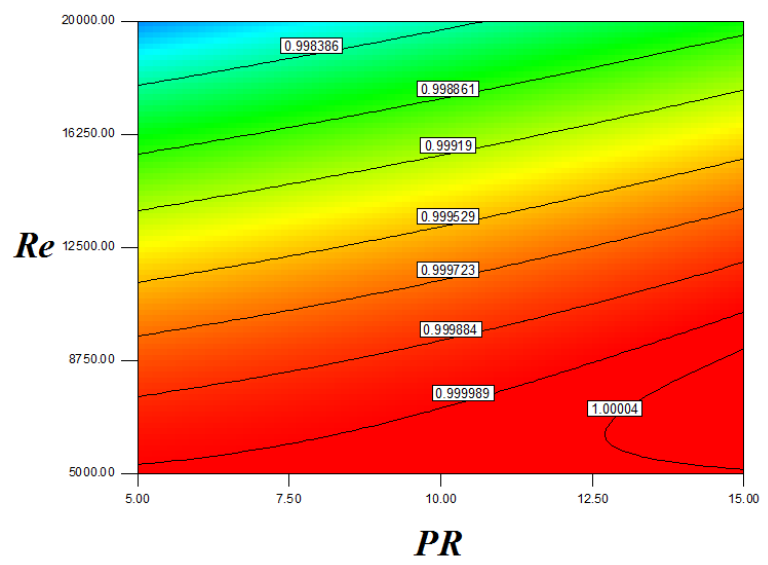

$B R=0.4$

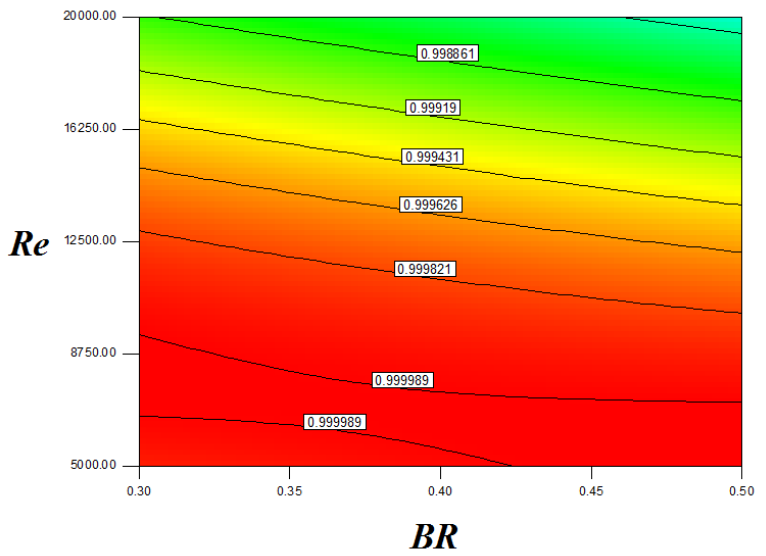

$P R=10$ 

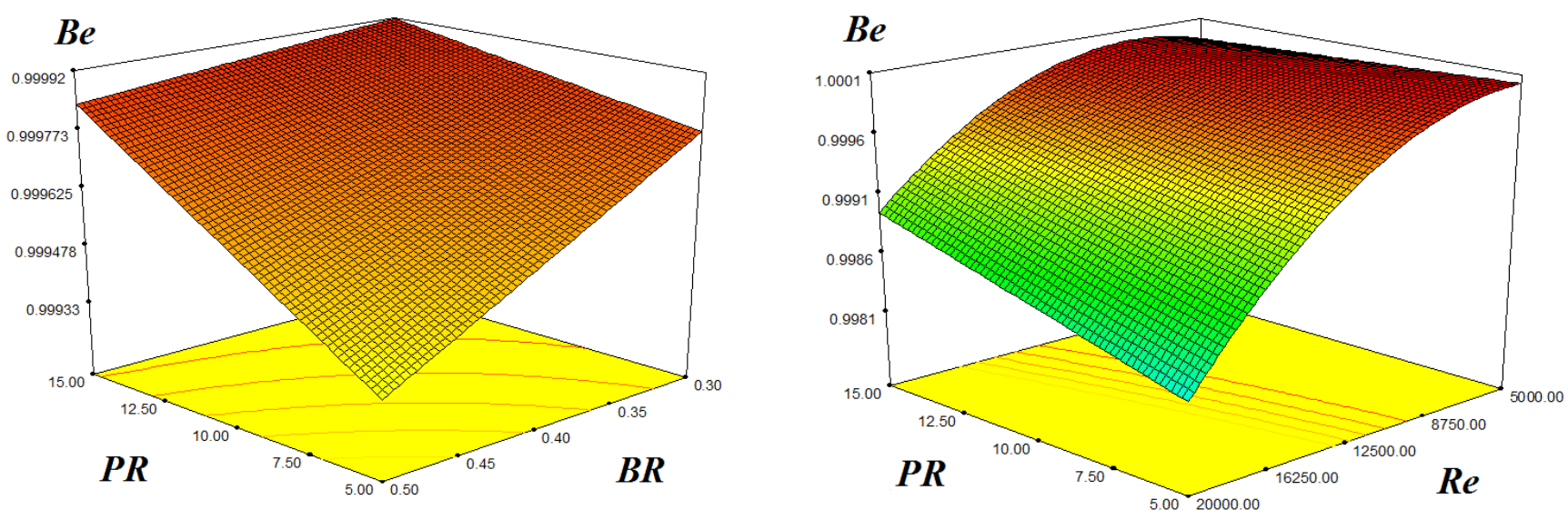

$$
\operatorname{Re}=10250 \quad B R=0.4
$$

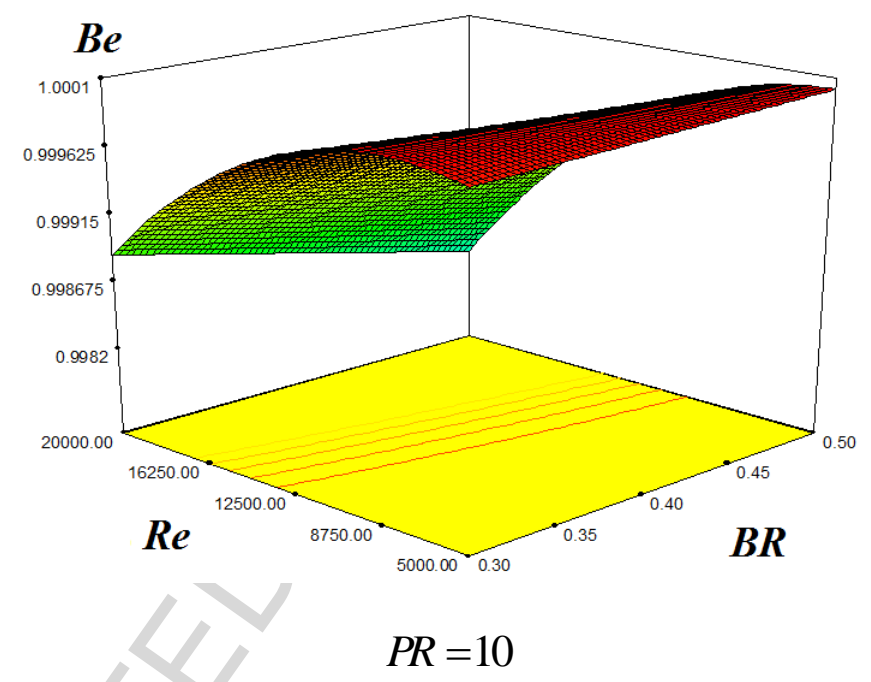

Fig. 8. Effect of Re, PR and BR on Bejan number 
Table1. The coefficient values of $\mathrm{CuO}-$ Water nanofluid

\begin{tabular}{cc}
\hline Coefficient values & CuO-Water \\
\hline$a_{1}$ & -26.5933108 \\
$a_{2}$ & -0.403818333 \\
$a_{3}$ & -33.3516805 \\
$a_{4}$ & -1.915825591 \\
$a_{5}$ & $6.421858 E-02$ \\
$a_{6}$ & 48.40336955 \\
$a_{7}$ & -9.787756683 \\
$a_{8}$ & 190.245610009 \\
$a_{9}$ & 10.9285386565 \\
$a_{10}$ & -0.72009983664 \\
\hline
\end{tabular}

Table2. Thermo physical properties of water and nanoparticles

\begin{tabular}{ccccc}
\hline & $\rho\left(\mathrm{kg} / \mathrm{m}^{3}\right)$ & $C_{p}(j / \mathrm{kgk})$ & $k(\mathrm{~W} / \mathrm{m.k})$ & $\mu($ Pa.s $)$ \\
\hline Pure water & 997.1 & 4179 & 0.613 & 0.0010003 \\
$\mathrm{CuO}$ & 6500 & 540 & 18 & - \\
\hline
\end{tabular}

Table3. Solver Setting of ANSYS FLUENT

\begin{tabular}{ccc}
\hline Solver & \multicolumn{2}{c}{ Pressure-Based, Steady } \\
\hline Viscous model & $K-\varepsilon, R N G$, Enhanced wall treatment \\
\hline \multirow{2}{*}{ Solution methods } & Pressure-velocity coupling & SIMPLE \\
& Gradient & Green-Gauss node based \\
& Pressure & Standard \\
\hline \multirow{2}{*}{ Spatial Discretization } & Momentum & Second order upwind \\
& Turbulent kinetic energy & Second order upwind \\
& Turbulent dissipation rate & Second order upwind \\
\hline
\end{tabular}


Table4. Grid independence test for $P R=5, B R=0.5, \operatorname{Re}=20000$

\begin{tabular}{cccc}
\hline Mesh & $\begin{array}{c}\text { Total element } \\
\text { number }\end{array}$ & $\boldsymbol{N u}$ & $\boldsymbol{f}$ \\
\hline Very coarse mesh & 201134 & 180.105 & 0.092 \\
Coarse mesh & 310221 & 180.024 & 0.094 \\
Normal mesh & 522892 & 179.876 & 0.095 \\
Fine mesh & 1001312 & 179.581 & 0.096 \\
Very fine mesh & 1378654 & 179.478 & 0.096 \\
\hline
\end{tabular}

Table5. Ranges of $Y^{+}$for when $\operatorname{Re}=20000$

\begin{tabular}{ccc}
\hline Case & Surface & $Y^{+}$ \\
\hline$P R=15, B R=0.3$ & Outer Wall & 3.653840085 \\
& twisted tape wall & 3.329417279 \\
$P R=15, B R=0.5$ & Outer Wall & 3.162444045 \\
& twisted tape wall & 2.958740417 \\
$P R=5, B R=0.3$ & Outer Wall & 4.252006463 \\
& twisted tape wall & 3.592632247 \\
$P R=5, B R=0.5$ & Outer Wall & 4.419943403 \\
& twisted tape wall & 3.678451027 \\
\hline
\end{tabular}




\section{Highlights}

$>$ Entropy generation for nanofluid turbulent flow is presented.

$>$ FVM is selected for numerical approach.

$>$ Bejan number enhance with augment of BR and PR

$>$ Total entropy generation increases with augment of BR and PR 